\title{
Consonants /s/ / / / / and the Syllables in Malay Language
}

\author{
Syatirah Mat Zin, Fatanah M. Suhaimi*, Siti Noor Fazliah Mohd Noor, NurulIffah Ismail, \\ Nurulakma Zali \\ Craniofacial and Biomaterial Sciences Cluster, Advanced Medical and Dental Institute, Universiti Sains \\ Malaysia, 13200 Bertam Penang, Malaysia.
}

* Corresponding author. Tel.: +6046535999; email: fatanah.suhaimi@usm.my

Manuscript submitted April 1, 2016; accepted July 10, 2016.

doi: 10.17706/ijbbb.2016.6.3.92-98

\begin{abstract}
Language is a medium for communication between humans. Language used code which is a combination of phonemes that form words and sentences. Each word has one or more syllables, while the combination of vowel and consonants will produce syllables. Articulation process involves the function of several human systems such as respiratory system, throat, voice cord and vellum working together in combinations ensuring perfect production of sound and speech. Each alphabet produces pattern on the tongue and hard palate contact as they were pronounced. This paper presents a pilot study on the production of $/ \mathrm{s} /, / \mathrm{t} /$ and $/ \mathrm{l} /$, and the syllables by an adult speaker using an Electropalography (EPG). The participant, who speaks Malay as her first language recorded the production of $/ \mathrm{s} / \mathrm{t} / \mathrm{t} / \mathrm{and} / \mathrm{l} /$ and the syllables. The Reading EPG palate used in this study has 62 electrodes which matched the tongue-palate contact. Data was analyzed using Articulate Assist 1.18. The purpose of this study is to observe the differences of tongue-palate contact between the consonants /s/, /t/ and /l/. Results indicate significant differences between production of $/ \mathrm{s} /, \mathrm{t} / \mathrm{and} / \mathrm{l} /$ with the syllables.
\end{abstract}

Key words: Electropalatograph, syllables, Malay language.

\section{Introduction}

Electropalatograh (EPG) is a device used to monitor contacts between the tongue and hard palate, particularly during articulation and speech. EPG has many advantages which include the ability to provide real-time visual feedback of tongue-palate contacts [1]. EPG helps to overcome speech problem that may arise from defective palate development such those observed in cleft palate subjects [2]-[6]. EPG is also suitable as a method for language analyses [7], [8]. EPG provides a safe and convenient technique for recording the timing and location of tongue contact with the hard palate during a continuous speech [1]. Although EPG has shown potentials as a tool for speech therapy, this technique is not very common and popular in Malaysia. Hence, most of the studies involved English speaker and very few from other languages including Japanese, Cantonese and Hindi [5], [9], [10]. In this study, EPG is used to analyse articulation in Malay syllable.

Language uses code which is a combination of phonemes that form words and sentences that produces meaning [11], [12]. A language is a form of communication between humans to represent objects, actions, ideas and situations. Identifying the main differences between human languages is difficult [13]. 
Interestingly, EPG can be used for analyzing syllables in the Malay language. Each word has one or more syllables. The combination of vowel and consonants will produce syllables. Additionally, each consonant and vowel have their unique production. This production comes from the contact between tongue and palate.

During the process of articulation, several human systems play a role in the course of this articulation. The systems involve in articulation include the respiratory system, throat, voice box and vellum [14]. Each alphabet produced a pattern upon contact between palate and tongue [7].

In this study, three consonant were selected which are /s/, /l/ and /t/. Vowel /a/, /i/ and /u/ were also used with the consonants to produce syllables. The patterns of the syllables on the EPG palate were analysed using the Articulate Assistant TM Version 1.18.

\section{Materials and Methods}

\subsection{Subject}

In this pilot study, a 32 year old female native Malay speaker has been selected as the test subject. She does not have any history of speech, language or hearing difficulties, and is medically fit. She speaks Malay as her first languageand was well trained to use the EPG palate and system. This study has been approved by the Internal Review Board of Universiti Sains Malaysia Human Ethics Committee. The subject was required to wear a customized Reading palate during the procedure.

\subsection{Materials}

In this study, the Reading Palate is used to monitor the tongue-palate contacts. The Reading Palate was originally built at the University of Reading in the mid-1980s [1]. The connector board will be plugged into the board reader called a multiplexer. The software, Articulate Assist 1.18 was used to analyse the data. The Reading palate consists of 62 silver contacts embedded in an acrylic resin that covers the palatal surface [1], [15]. Stainless steel Adams clasps clip were embedded around the first permanent molar teeth to retain the palate in place [15].

\subsection{Procedures}

Table 1. Collocation between Vowels and Consonants

\begin{tabular}{clll}
\hline \hline Alphabet & s & l & t \\
\hline & & & \\
a & as & al & at \\
i & Is & il & It \\
u & us & ul & ut \\
\hline \hline
\end{tabular}

A full plaster of Paris (gypsum) study model was first fabricated from the subject's upper palate impression imprint and teeth using conventional dental impression taking and pouring procedures. The upper arch impression must be accurate and free of bubbles. After that, the acrylic plate was casted on the study model. The acrylic plate must be as thin as possible to ensure no or minimal interference with normal speech production [1]. The subject is required to wear the artificial plate for at least 30 minutes to one hour before the first recording for acclimatization to the plate. This is to allow the subject to become accustomed to the sensation of an unfamiliar object in the mouth [1]. The subject was required to record their sound of voice samples in a sound-proof room with a microphone at a distance of $15 \mathrm{~cm}$ from her mouth [1]. The subject was asked not to look at the EPG display on the computer screen while recording to obtain natural speech production. During speech production, the artificial palate will transmit the tongue-palate contact information to the computer. Table 1 shows the collocation between vowels and consonants.These three 
vowels were chosen to collocate with a consonant in Malay speaker. By using these three vowels, differences among the syllables will be magnified.

\section{Result and Discussion}

\subsection{Consonant $/ \mathrm{t} / / \mathrm{s} / / \mathrm{l} /$}

Fig. 1 shows the pattern of consonant /t/ in different syllables. These syllables start with vowel /a/, /i/, $/ \mathrm{u} /$ and end with consonant $/ \mathrm{t} /$. From this figure, it can be observed that there are slight differences between /t/ and the syllables. In the production of /t/, /at/ and / ut/ there are seven electrode contacts between the palate and tongue at the alveolar zone. However, there are six contacts between palate and tongue in the production of /it/. This shows that only one different contact point exist at the alveolar zone. At post-alveolar zone, there are seven electrode contacts in the production of /t/, /at/ and /ut/ and six electrode contacts in the production of /it/. There are five electrode contacts in the production of $/ \mathrm{t} /$ and /it/ at the palatal zone. Two electrode contacts in the production of /at/ and one electrode contact in the production of /ut/. While at the velar zone, there are three electrode contacts in the production of $/ \mathrm{t} /$ and /it/, two electrode contacts in the production of /at/ and one electrode contact in the production of /ut/. The total electrode contact in the production of /t/, /at/, /it/ and /ut/ are 22 electrodes, 18 electrodes, 20 electrodes and 16 electrodes, respectively. There are minimal differences observed between the production of / $t$ / with /it/ and marked differences between the production of / $t$ / with /at/and / ut/.

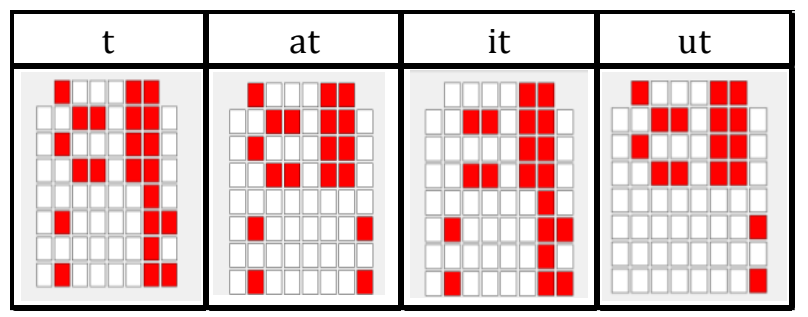

Fig. 1. Pattern of consonants / $t$ / in different syllables.

Fig. 2 shows the pattern of consonant /s/ in different syllables. In the production of /s/ there are nine electrode contacts between the tongue and palate in the alveolar zone and there are five contacts in the production of /as/, four contacts in the production of /is/ and three contacts in the production of /us/. In post-alveolar zone, there are nine electrode contacts in the production of $/ \mathrm{s} /$, five contacts in the production of /as/, four electrodes in the production of /is/ and three electrodes in the production of /us/. In the palatal zone, two electrodes were in contact in the production of /s/, /is/ and /us/ whereas one contact in the production of /as/. While in the velar zone, two electrode contacts were observed during the production of /is/ and /us/, one in the production of /as/ and no electrode contact in the production of /s/. The total electrode contact in the production of /s/, /as/, /is/ and /us/ are 20 electrodes, 12 electrodes, 12 electrodes and 10 electrodes, respectively.

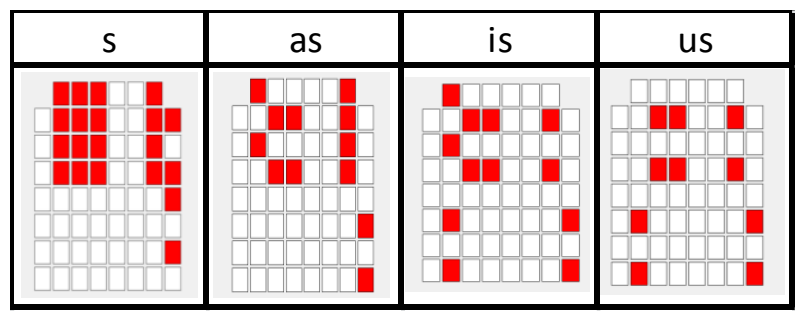

Fig. 2. Pattern of consonants /s/ in different syllables. 
Fig. 3 shows the pattern of consonant /l/ in different syllables, the syllables ends with the consonant /l/ and begins with vowel /a/, /i/, /u/. In the production of /l/ and /al/, there are seven electrode contacts between tongue and palate at the alveolar zone. However, there are six contacts between palate and tongue in the production of /il/ and /ul/. In post-alveolar zone, there are seven electrode contacts between tongue and palate. However, there are six contacts in the production of /il/ and /ul/. There are no electrode contacts in the production of $/ \mathrm{l} / \mathrm{d} / \mathrm{al} /$ and $/ \mathrm{ul} /$ in the palatal zone, whereas three electrode contacts in the production of /il/. There are three contacts in the production of /il/ and no electrode contact in the production of /l/, /al/ and /ul/ in velar zone. Total electrode contacts in production of /l/, /al/, /il/ and /ul/ are 14 electrodes, 14 electrodes, 18 electrodes and 12 electrodes, respectively.

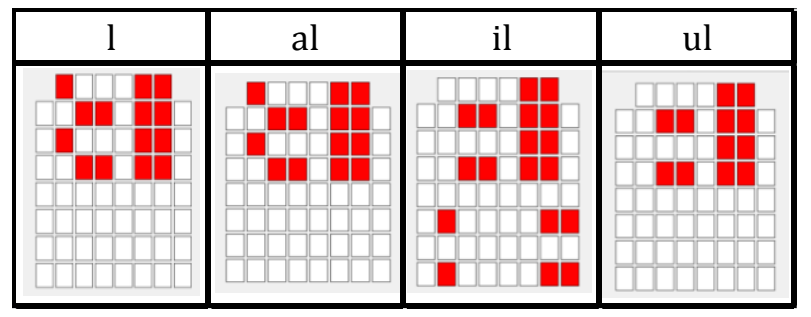

Fig. 3. Pattern of consonants $/ \mathrm{l} /$ in different syllables.

Table 2 summarizes the percentage of contact between the tongue and palate against consonant $/ \mathrm{t} / \mathrm{,} / \mathrm{s} /$, /l/ and the syllables. From the table, the production of /t/, /at/, /it/ and /ut/ have the highest contact in the alveolar zone, followed by post-alveolar, velar and palatal. The percentage is $50 \%$ at the production of /t/, /at/ and /ut/ and 43\% at the production of /it/. At post-alveolar zone, the percentage is $44 \%$ for the production of /t/, /at/ and /ut/ and 38\% at the production of /it/. Meanwhile at the palatal zone, the percentage for the production of $/ \mathrm{t} /$ and /it/ is $38 \%$, the production of /at/ is $25 \%$ and the production of /ut/ is 13\%. Palatal zone shows the lowest contact compared to other zones. At the production of / $\mathrm{t} /$ and /it/ the percentage is $21 \%$, /at/ is $8 \%$ and /ut/ is $4 \%$.

Table 2. Percentage Contact of Consonant / $\mathrm{t} /$ and Syllables

\begin{tabular}{|c|c|c|c|c|c|c|c|c|c|c|c|c|}
\hline Zone & $\mathrm{t}$ & at & it & ut & $\mathrm{s}$ & as & is & us & l & al & il & ul \\
\hline Alveolar & 50 & 50 & 43 & 50 & 64 & 36 & 29 & 21 & 50 & 50 & 43 & 43 \\
\hline Post-alveolar & 44 & 44 & 38 & 44 & 56 & 31 & 25 & 19 & 44 & 44 & 38 & 38 \\
\hline Palatal & 21 & 8 & 21 & 4 & 8 & 4 & 8 & 8 & 0 & 0 & 13 & 0 \\
\hline Velar & 38 & 25 & 38 & 13 & 0 & 13 & 25 & 25 & 0 & 0 & 38 & 0 \\
\hline
\end{tabular}

Similarly, the highest percentage of contact for the production of /s/ with variation of syllables is at alveolar zone followed by post alveolar, velar and palatal. The percentage of contact for production of /l/ and its syllables at alveolar and post-alveolar are similar to consonant /t/. However, palatal and velar zone have the lowest contact compared to others production.

\subsection{Differences between $/ \mathrm{t} / / \mathrm{s} / / \mathrm{l} /$ and Syllables and Palate Zone}

Fig. 4 shows the percentage of contact against the palate zone. The production of $/ \mathrm{s} /, / / \mathrm{t} / \mathrm{and} / \mathrm{l} / \mathrm{shows}$ the highest contact at the alveolar zone followed by post-alveolar. The /s/ and /l/ have similar pattern of contact for the four different palate zones. However, the production of $/ \mathrm{t} /$ is slightly different compared to /s/ and /l/ particularly at the velar zone. All three consonants have low palate contact at the palatal and 
velar zones.

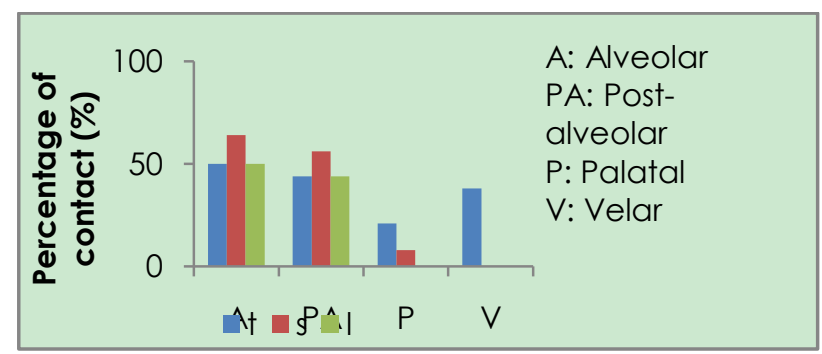

Fig. 4. Percentage of contact against palate zone.

Fig. $5 a, 5 b$ and $5 c$ show the percentages of the contact against palate zone for the production of vowel /a/, /i/ and /u/. From the figure, the highest contacts were obtained at the alveolar zone whereas the lowest contact was observed at the palatal zone. Combining each of the consonant with a specific vowel produced a similar contact pattern throughout the different palate zones. This indicates the uniqueness of the vowel which forms the basis of the syllables.

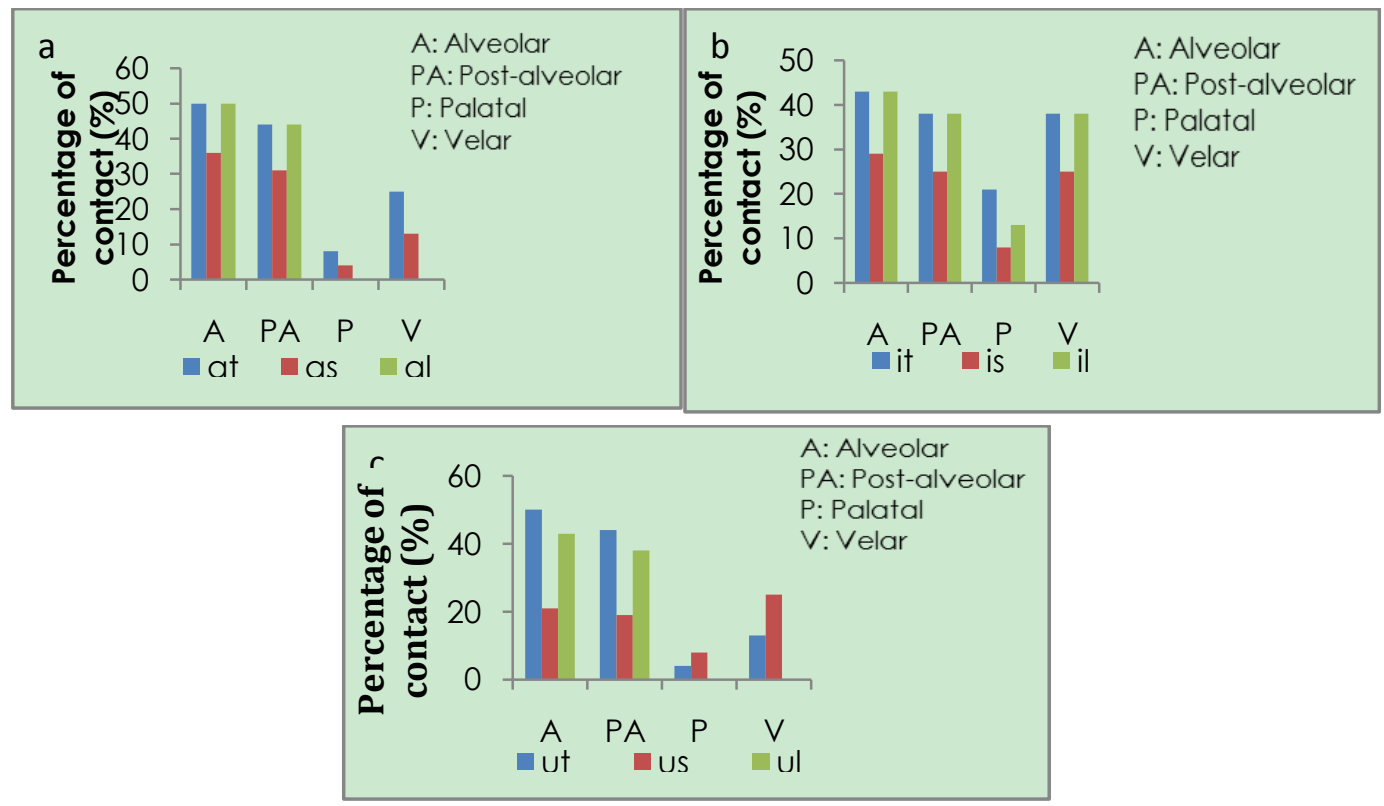

Fig. 5. (a) Percentage of contact against palate zone for vowel /a/. (b) Percentage of contact against palate zone for vowel /i/. (c) Percentage of contact against palate zone for vowel /u/.

The tongue adhered and created strong contact with the alveolar and also with the post-alveolar during the production of /s/, /t/ and /l/ and the syllables. However, a less strong contact which is weak was observed when the tongue is in contact with the palatal zone during the production for each consonant and the syllables [10]. This study indicates that the characteristic of a vowel will affect the contact pattern.

\section{Conclusion}

The productions of vowel depend on the condition of the oral cavity. Tongue plays a role in this activity because it will move up and down, and at the same time controlling the size of the mouth with the facial muscles. The production of vowel occurs without any restrictions on the flow of air which exist throughout the system and its production are also different from one language to other languages. These findings showed that the vowel /a/, /i/ and /u/ can change the pattern contact between the tongue and the palate. 
Hence, each vowel has its characteristics which help to change the pattern. However, this study needs to improve in the future. Researchers should use three or more subjects for comparison, and therefore ensuring more accurate readings can be obtained. Subject needs to wear the training palate at least 4 hours before he or she records the readings. Longer time may be needed for subject to adjust himself/herself and feel comfortable with the Reading Palate.

\section{Acknowledgment}

This study was conducted at the Craniofacial and Biomaterial Science Cluster, Advanced Medical and Dental Institute, USM. Authors would like to acknowledge the financial support provided by the Ministry of Science, Technology and Invasion (MOSTI). This study is part of the project granted by Science Fund Grant (Project no: 06-01-05-SF0718).

\section{References}

[1] Hardcastle, W., et al. (1989). New developments in electropalatography: A state-of-the-art report. Clinical Linguistics \& Phonetics, 3(1), 1-38.

[2] Carter, P., \& Edwards, S. (2004). EPG therapy for children with long-standing speech disorders: Predictions and outcomes. Clinical Linguistics \& Phonetics, 18(6-8), 359-372.

[3] Chi-Fishman, G., \& Stone, M. (1996). A new application for electropalatography: Swallowing. Dysphagia, 11(4), 239-247.

[4] Goozee, J. V., Murdoch, B. E., \& Theodoros, D. G. (2003). Electropalatographic assessment of tongue-to-palate contacts exhibited in dysarthria following traumatic brain injury: Spatial characteristics. Journal of Medical Speech-Language Pathology, 11(3), 115-129.

[5] Hardcastle, W. J., Gibbon, F. E., \& Jones, W. (1991). Visual display of tongue-palate contact: Electropalatography in the assessment and remediation of speech disorders. British Journal of Disorders of Communication, 26(1), 41-74.

[6] McMicken, B. L., et al. (2014). Electropalatography in a case of congenital aglossia. Journal of Communication Disorders, Deaf Studies \& Hearing Aids.

[7] McLeod, S., Roberts, A., \& Sita, J. (2006). Tongue/palate contact for the production of/s/and/z. Clinical Linguistics \& Phonetics, 20(1), 51-66.

[8] McAuliffe, M. J., \& Cornwell, P. L. (2008). Intervention for lateral/s/using electropalatography (EPG) biofeedback and an intensive motor learning approach: A case report. International Journal of Language \& Communication Disorders, 43(2), 219-229.

[9] Dixit, R. P., \& Hoffman, P. R. (2004). Articulatory characteristics of fricatives and affricates in Hindi: An electropalatographic study. Journal of the International Phonetic Association, 34(02), 141-159.

[10] Yu, H., Duan, Y., \& Liu, X. (2013). The research on articulation places of mandarin Chinese consonants from perspective of EPG. 2013 International Workshop on Computer Science in Sports. Atlantis Press.

[11] Abd, K., Ghani, \& Nik, M. R. (2000). Pengaruh bahasa Melayu ke atas sebutan bahasa Arab dan kemahiran tilawah al-Quran. Jurnal Sari., 18, 67-79.

[12] Jakobson, R., \& Halle, M. (2002). Fundamentals of Language. Walter de Gruyter.

[13] Jabar, A., \& Azidan, M. (2004). Gangguan bunyi Melayu dalam sebutan Arab: Satu analisis ringkas. Pertanika Journal of Social Sciences \& Humanities, 12(2), 101-110.

[14] Zahid, I. H., \& Omar, M. S. (2006). Fonetik dan fonologi. Akademia.

[15] Wrench, A. A. (2007). Advances in EPG palate design. Advances in Speech Language Pathology, 9(1), 3-12. 


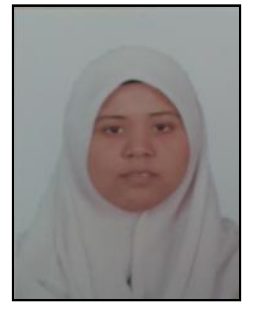

Syatirah Mat Zin was born on 17th March 1984 in Kedah, Malaysia. She received the B.Eng. (honours) in biomedical engineering from Universiti Malaya, Malaysia in 2007, and a master degree in technical and vocational education from Universiti Tun Hussien Onn Malaysia, Malaysia in 2012.

Her current appointment is a Ph.D student at the Craniofacial and Biomaterial Sciences Cluster, Advanced Medical and Dental Institute, Universiti Sains Malaysia.

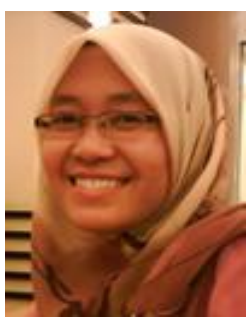

Fatanah M Suhaimi was born on $5^{\text {th }}$ November 1984 in Manchester, England. She received the B.Eng. (honours) in mechatronic engineering from International Islamic University Malaysia in 2008, and a Ph.D degree in mechanical engineering from University of Canterbury, New Zealand in 2012.

Her current appointment is a lecturer of the Craniofacial and Biomaterial Sciences Cluster, Advanced Medical and Dental Institute, Universiti Sains Malaysia. She had published more than 20 scientific papers, peer-reviewed conference proceedings and abstracts.

Dr. Suhaimi research interests are in mathematical modelling of biological system, medical laser, and rehabilitation engineering.

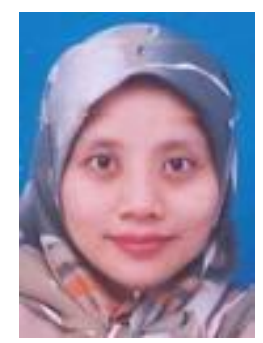

Siti Noor FazliahMohd Noor was born on $2^{\text {nd }}$ January 1973 in Johore, Malaysia. She received the bachelor of dental surgery in May 1997 and completed the master in clinical dentistry (child dental health) in August 2004 from Universiti Malaya. She completed training in oral surgery (MFDS), from the Royal College of Surgeon of England in 2008, and has completed a Ph.D in biomaterials and stem cells from Imperial College London, United Kingdom in 2015.

Her current appointment is as senior lecturer of the Craniofacial and Biomaterial Sciences Cluster, cum Paediatric Dentistry Consultant, Advanced Medical and Dental Institute, Universiti Sains Malaysia. She had published more than 30 scientific papers, peer-reviewed conference proceedings and abstracts.

Dr. Mohd Nor has research interests in craniofacial development and anomalies, biomaterials and stem cells.

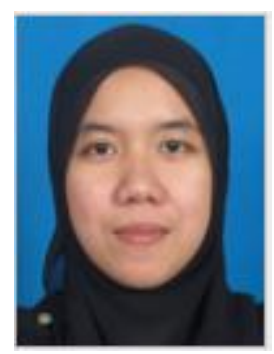

NurulIffah Ismail was born on $5^{\text {th }}$ May 1987 in Alor Setar, Kedah. She received the B.Eng (honours) in chemical engineering from Universiti Sains Malaysia in 2012.

She is currently works as research assistant at Craniofacial and Biomaterial Science Cluster, Advanced Medical and Dental Institute (AMDI), Universiti Sains Malaysia.

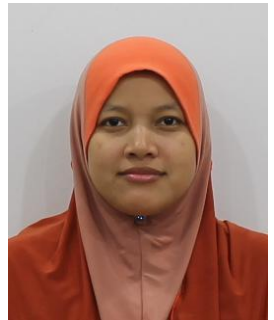

Nurulakma Zali was born on $12^{\text {th }}$ April 1985 in Pasir Mas, Kelantan. She received the bachelor (honours) in science (chemistry) from Universiti Teknologi MARA in 2007. Her current appointment is a science officer of the Craniofacial and Biomaterial Sciences Cluster, AMDI, Universiti Sains Malaysia. Nurulakma Zali research interests are in biomedical laser and biomaterial. 